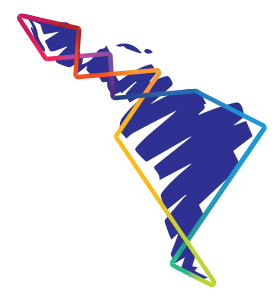

\title{
Del derecho al deber: La impronta ética de los derechos humanos a partir de la responsabilidad de proteger
}

\author{
From rights to duties: The ethical \\ imprint of human rights based on \\ the responsibility to protect
}

Ana María Bonet de Viola ${ }^{1}$

Federico Ignacio Viola²

\section{Resumen}

El objetivo de este trabajo es proponer, desde una perspectiva ética, un replanteo del principio de "responsabilidad de proteger". Se parte de la premisa de que la violencia generada por la intervención sobre cualquier alteridad es un reflejo de la raigambre moderna del derecho vigente y sus postulados individualistas, basados en la defensa a ultranza de la identidad. Se propone revisar estos postulados a través de una reformulación del concepto jurídico de

1 Investigadora Universidad Católica de Santa Fe - CONICET (Consejo Nacional de Investigaciones Científicas y Técnicas - Argentina). Doctora en Derecho (Universidad de Bremen, Alemania), Master en Derecho - LLM (Universidad de Friburgo, Alemania), Abogada (UNL, Argentina), Mediadora. Directora del Proyecto de Investigación "Fraternidad como camino para la paz. Aportes para repensar los derechos humanos a partir de su potencial ético-relacional", UCSF, Argentina. Correo electrónico: anamaria.bonetdeviola@gmail.com. ORCID: https://orcid.org/0000-0002-9991-5475

2 Investigador asistente del CONICET (Consejo Nacional de Investigaciones Científicas y Técnicas) con lugar de trabajo en el Instituto de Filosofía de la Universidad Católica de Santa Fe - Argentina. Doctor en Filosofía (Universidad de Friburgo, Alemania), Licenciado en Filosofía (Universidad Nacional del Litoral, Arg.). Entre 2013 y 2015 Docente en la Universidad de Friburgo y en la Universidad de Koblez-Landau. Autor del libro "Der Kairos der Liebe. Das Konzept der Gerechtigkeit bei Emmanuel Levinas" y de publicaciones académicas aparecidas en revistas científicas de Europa y América Latina. Correo electrónico: federicoviola@gmail.com. ORCID: https://orcid.org/0000-0001-6845-9270. 
responsabilidad de proteger, en vistas a proponer un abordaje ético de los derechos humanos, en tanto derechos de la alteridad. Ello significa, en definitiva, un replanteo de los términos de la convivencia global: la socialidad no se constituye como adición de identidades, sino como desmesura de responsabilidades.

Palabras clave: Responsabilidad de proteger, derechos humanos, derechos del otro, ética, derecho internacional público.

\begin{abstract}
The objective of this work is to propose, from an ethical perspective, a rethinking of the principle of "responsibility to protect". It starts from the premise that the violence generated by the intervention on any alterity is a reflection of the modern roots of contemporary rights and its individualistic postulates, based on the extreme defense of identity. It is proposed to review these postulates through a reformulation of the legal concept of responsibility to protect, in order to propose an ethical approach to human rights, as rights of alterity. This means, in definitive, a rethinking of the terms of global coexistence: sociality is not constituted by addition of identities, but as an excess of responsibilities.
\end{abstract}

Keywords: Responsibility to protect; Human rights; Rights of otherness; Ethics; Public international law.

\title{
Resumo
}

O objetivo deste trabalho é propor, em uma perspectiva ética, um repensar do princípio da "responsabilidade de proteger". Parte-se do pressuposto de que a violência gerada pela intervenção em qualquer alteridade é um reflexo das raízes modernas do direito vigente e seus postulados individualistas, baseados na extrema defesa da identidade. Propõe-se a revisão de seus postulados por meio de uma reformulação do conceito jurídico da responsabilidade de proteger, a fim de propor uma abordagem ética dos direitos humanos, como direitos da alteridade. Isso significa, definitivamente, repensar os termos da convivência global: a socialidade não se constitui como um acréscimo de identidades, mas como um excesso de responsabilidades.

Palavras-chave: Responsabilidade de proteger; Direitos humanos; Direitos do outro; Ética; Direito internacional público.

\section{Introducción}

El principio de la 'responsabilidad de proteger' surge institucionalmente en el ámbito de la Organización de Naciones Unidas (ONU), para establecer jurídicamente el deber de los Estados de proteger a las poblaciones en situación de emergencia humanitaria. El concepto teórico es incubado en el seno de una Comisión Internacional sobre Intervención y Soberanía de los Estados, impulsada y financiada por el gobierno de Canadá. En 2001 esta comisión presenta un informe sobre el tema 
que servirá de puntapié al secretario general de Naciones Unidas, Kofi Annan, para introducir el concepto en la Organización.

El Documento final de la Cumbre Mundial de 2005 (AGNU, 2005) se refiere explícitamente a la "responsabilidad de proteger a las poblaciones frente al genocidio, los crímenes de guerra, la depuración étnica y los crímenes de lesa humanidad" (párr. 139). Los párrafos 138 a 140 de la Resolución se basaron en un Informe del secretario general Kofi Annan (2005) titulado "Un concepto más amplio de libertad: desarrollo, seguridad y derechos humanos para todos", el cual, a su vez, se inspiró en los informes "Un mundo más seguro: la responsabilidad que compartimos" del Grupo de Alto Nivel sobre las amenazas, los desafíos y el cambio (GAN, 2004) y "La responsabilidad de proteger" de la Comisión Internacional sobre Intervención y Soberanía de los Estados (ICISS, 2001), impulsado por el gobierno de Canadá (Añaños Meza, 2010).

Según la configuración vigente del principio en los párrafos enunciados, tales violaciones estarían taxativamente limitadas al genocidio, los crímenes de guerra, la depuración étnica y los crímenes de lesa humanidad. Una cuestión no menor en relación con ello consiste en la prerrogativa de determinación de la existencia de tales violaciones que, por tratarse de tipos penales, tal prerrogativa debería ser atribuida a un tribunal competente, con todos los vaivenes procedimentales que ello significa (Añaños Meza).

Si bien este principio técnicamente tan solo habilita el accionar de los Estados frente a tales casos, incorpora, a su vez, teóricamente, de alguna manera, y en este punto recae el análisis de este artículo, una apelación a un deber primario de los Estados y a una responsabilidad subsidiaria de la comunidad internacional de velar por el respeto de los derechos humanos a nivel global (Añaños Meza, 2010; López-Jacoiste Díaz, 2006).

Este abordaje extensivo del concepto de responsabilidad de proteger implicaría, técnicamente, la expansión de sus ámbitos de aplicación, en sus dimensiones personal, material y territorial. La extensión del ámbito de aplicación personal tendría lugar al establecer como respectivos obligados y beneficiarios a todos los miembros de la comunidad global y no solo al Estado particularmente involucrado. Por su parte, la extensión del ámbito de aplicación material se ampliaría por el reconocimiento, como supuestos de aplicación, no solo de los cuatro casos enumerados en la nombrada resolución, sino de todos aquellos donde se viola algún derecho humano. Finalmente, la extensión territorial coincide con la institución de deberes extraterritoriales, es decir, exigibles más allá de las fronteras de los Estados. 
Si bien el principio en cuestión surge como una contribución a un firme proceso de consolidación de los derechos humanos, su aplicación, sin embargo, no está libre de controversias. Pues desestabiliza postulados fundamentales del derecho internacional público (DIP) como el principio de 'no uso de la fuerza' y el de 'no intervención'. Junto con la desestabilización de este último postulado, cuestiona incluso el concepto mismo de soberanía (Añaños Meza, 2010; López-Jacoiste Díaz, 2006), por lo menos en su sentido clásico.

Este espíritu revisionista se encauza en una coyuntura del DIP que, desde fines de la Segunda Guerra Mundial, se redefine ya no solo como regulador de las relaciones entre los Estados, sino también como gestor de derechos fundamentales individuales. La realización efectiva de estos derechos excede el marco de las fronteras estatales y por eso requiere de una gestión transnacional.

El DIP surge con la consolidación de los Estados modernos, a partir de la segunda mitad del siglo XVII. Desde entonces y hasta el fin de la Segunda Guerra Mundial, se limitaba a regular las relaciones entre los Estados soberanos. La regulación de los derechos de los individuos permanecía como cuestión de orden interno. La creación de Naciones Unidas significa, al respecto, un gran cambio, pues su Carta fundante le asigna, como propósito, el desarrollo y el estímulo del respeto a los derechos humanos y libertades fundamentales (Cap. I.3), lo cual implica incorporar la cuestión de los derechos individuales a la agenda del derecho internacional (Barboza 2008; Diez de Velasco, 2013).

La concepción de los derechos humanos que sustentó su proceso de institucionalización normativa internacional se inspiró, en efecto, en la doctrina jurídica moderna occidental de corte liberal, basada en una filosofía individualista y un orden hegemónico transnacional (Añaños Meza, 2010). De esta forma, el derecho internacional asumió de facto una misión civilizatoria universal, que justificó la expansión global del Estado de derecho y sus postulados fundantes de legalidad y seguridad jurídica. Estos, a su vez, se convirtieron en la garantía del status quo defendido por un sujeto ideal de derechos -individual, autónomo, libre y soberano- ya sea este humano o estatal.

En nombre de la seguridad, es decir, en vistas de asegurar la posición privilegiada del sujeto soberano y autónomo, el derecho transforma cualquier amenaza de desestabilización del orden instituido en una violación jurídica. En el marco de este derecho propiciador del orden y de una renovada preocupación por la seguridad humana, surge el principio de responsabilidad de proteger (Leal Moya, 2005; Luengo Zarzoso, 2016; Cendejas Guízar/Merino Pérez, 2016). En efecto, aunque discursivamente este principio puede comprenderse como instrumento de 
garantía de humanidad, en la práctica corre el riesgo de reforzar la posición de las identidades modernas, soberanas, hegemónicas y absolutistas; y, por lo tanto, de ir en contra, precisamente, de aquello que quiere preservar y promover. A través de la intervención sobre los Estados considerados "frágiles, fallidos o canallas" (Añaños Meza, 2010, p. 228), dicho principio corre el riesgo de transformarse en una nueva herramienta de imposición de los Estados centrales que ejercen la hegemonía global en nombre de la paz liberal (Chandler, 2004).

En esta lectura se torna evidente la paradoja de cómo un principio pretendidamente vanguardista como lo es la responsabilidad de proteger, en tanto aspira al desarrollo y protección de los derechos humanos, podría convertirse en el equivalente a una reivindicación del bellum iustum o guerra justa, considerada ya superada por la paz del Estado moderno (Añaños Meza, 2010; Howard, 2000), pues vendría a justificar toda intervención que reestablezca el orden formal de la paz liberal, que significa el reaseguramiento del status quo de la hegemonía de los Estados habilitados para intervenir.

En la arena del DIP, la discusión en torno a este principio se centra particularmente en sus alcances jurídicos, sobre todo en la determinación de los potenciales sujetos involucrados (activos y pasivos), así como en sus consecuencias teóricas y prácticas respecto de la coexistencia con otros principios del DIP, como son la igualdad soberana de los Estados, la no intervención y el derecho a la autodeterminación de los pueblos. El presente estudio se propone, en cambio, insistir en el potencial vanguardista de este principio, poniendo de relieve la impronta ética implícita en su misma conceptualización como responsabilidad de proteger.

A partir de una reapropiación de la noción de responsabilidad, se procurará realizar un aporte para una reformulación ética de este concepto, que traspase sus límites jurídico-formales. Se intentará demostrar que dicha reconceptualización implica no solo un mero cambio de concepción respecto de la figura antecesora de la 'intervención humanitaria', sino que, además y ante todo, encierra la posibilidad efectiva de un replanteo teórico radical en lo que refiere al discurso clásico vigente sobre los derechos humanos. Ello, en tanto que habilita el paso de un enfoque del orden jurídico basado en las pretensiones, las reivindicaciones y los derechos, a uno inspirado en la responsabilidad (López-Jacoiste Díaz, 2006) irrecusable y siempre urgente por los demás sujetos.

La intervención humanitaria constituye la habilitación de la intromisión de un sujeto del derecho internacional en los asuntos internos de otro, con el fin de responder a una emergencia humanitaria. Significa una excepción al principio de no intervención y, por eso, según el DIP, su habilitación debe ser interpretada 
restrictivamente. Algunos estudios la limitan al uso de la fuerza por parte de los Estados (Barboza, 2008) pero también podría darse a través de otras medidas como la ayuda humanitaria y por parte de otros sujetos del DIP como las organizaciones internacionales.

Aquello que en términos políticos significa la intromisión de un país en los asuntos internos de otro y en términos jurídicos, la violación del principio de no intervención, puede ser traducido en el debate filosófico acerca de la violencia generada por la irrupción de una identidad en la intimidad de otra. Se trata de la violencia presente en todo intervencionismo. El presente artículo se propone realizar una contribución iusfilosófica al debate jurídico-político sobre la vigencia del principio de no intervención, a través de una revisión crítica de las premisas filosóficas del discurso moderno liberal acerca de la seguridad y la violencia.

En un primer abordaje se analiza aquella forma de violencia ejercida por un Estado al "intervenir" en otro sin su consentimiento. En particular se hace hincapié en la funcionalidad que este principio puede asumir como mecanismo de legitimación de la intervención de los países centrales en los asuntos internos de países periféricos.

En un segundo análisis, se intenta poner de relieve la existencia de otra forma de violencia, tan primigenia como subrepticia y, por eso, no tan evidente, como es la violencia de la indiferencia. Se trata de la violencia generada por un sistema de convivencia global que asegura la hegemonía a ciertos Estados, librando al resto $a$ su propia suerte; es decir de la violencia que resulta del ejercicio de esta hegemonía, al anular las diferencias, tanto por medio de la marginación como de la asimilación en la propia identidad. Se parte de la premisa de que esta violencia tiene que ver con la raigambre moderna del derecho vigente y sus postulados individualistas, basados en la defensa a ultranza de la identidad.

La superación de la violencia 'intervencionista', la de la autoafirmación identitaria de un sujeto sobre otro, se alcanza evitando la intervención. En cambio, la de la segunda violencia, la de la indiferencia, exige una toma de posición activa, una apelación a una intervención en el asunto. Se trata de una intervención que no implica necesariamente una intromisión, sino que se traduce en un "hacerse cargo", esto es, en un asumir la carga de la 'responsabilidad' por la alteridad.

De esta forma se propone la incorporación de un cambio radical de perspectiva respecto de la concepción tradicional vigente que regula las relaciones entre Estados. La noción de responsabilidad incorpora un aspecto de gratuidad, un 'interés desinteresado' (Levinas, 2004), inconmensurable para la lógica del cálculo y la 
economía, y del cual se siguen particulares implicaciones prácticas. Sobre estos fundamentos teóricos y sus implicaciones prácticas trata el presente estudio.

A través de una resignificación del concepto de responsabilidad de proteger se buscará realizar un aporte para el desarrollo de otra forma de socialidad, ya no fundada en la hostilidad que significa la tensión entre identidades autorreferentes, sino inspirada en la hospitalidad, en la acogida de la alteridad (Derrida, 2001; Penchaszadeh, 2011). En este sentido, la propuesta de un abordaje ético de los derechos humanos significa, en definitiva, un replanteo de los términos de la convivencia global: la socialidad, en efecto, no se constituiría como adición de identidades -reunidas en el espacio común de lo público, pero mutuamente indiferentes las unas de las otras-. En cambio, la armonía tensa de la convivencia entre diferentes surgiría de la "extravagante hipótesis" de una desmesurada responsabilidad de todos por todos (Abensour, 1991, p. 89).

\section{Del derecho a intervenir a la responsabilidad de proteger}

Desde el punto de vista técnico-jurídico, la principal controversia en torno al principio de responsabilidad de proteger se concentra, particularmente, en la habilitación que otorga a los sujetos del DIP para intervenir en los asuntos internos de un Estado sujeto a ciertas emergencias humanitarias. El carácter de esta intervención consiste en una cuestión crucial, puesto que no solo implicaría una revisión del principio fundante del DIP, como es la no intervención, ${ }^{3}$ sino que además podría implicar una excepción al principio de no uso de la fuerza. ${ }^{4}$ Ello, a su vez, vendría a desestabilizar el monopolio mundial de la fuerza que se arroga el Consejo de Seguridad de Naciones Unidas. ${ }^{5}$

El mencionado Documento Final de la Cumbre de 2005, que instituye el principio de responsabilidad de proteger en el ámbito de la ONU se refiere, en primer lugar, a la utilización de medios pacíficos; sin embargo, a continuación admite la utilización de otras medidas, al hacer referencia al Capítulo VII de la Carta de Naciones Unidas, que habilita el uso de la fuerza al Consejo de Seguridad. Este último apartado generó un gran debate, sobre todo en tanto signifique la justificación de "medidas de fuerza", lo que para algunos estudios implicaría la rehabilitación de la doctrina

3 Se considera que el DIP surge a partir de la Paz de Westfalia (1648), cuando se instituye el principio de no intervención en los asuntos internos de otro gobierno (Barboza, 2008).

4 El principio de no uso de la fuerza surge recién luego de la segunda Guerra Mundial, junto con la Organización de Naciones Unidas (ONU). Antes la guerra no se consideraba prohibida, sino tan solo regulada (Barboza, 2008).

5 Según el artículo 7 de la Carta de Naciones Unidas, el Consejo de Seguridad tiene el monopolio internacional de la violencia, en tanto que es el único organismo autorizado a utilizar la fuerza, aunque de manera excepcional (cf. Barboza, 2008, p. 634). 
del bellum justum o guerra justa (Añaños Meza, 2010). En el ámbito del DIP, sobre todo luego de la Segunda Guerra Mundial, este concepto se suponía ya superado a través de los principios de "no uso de la fuerza" y de "solución pacífica de controversias", establecidos como pilares fundantes de la ONU (cf. Res. 2625 AGNU, 24/10/1970). Por ello otros estudios encuentran, en esta forma de intervención, incluso indicios de un supuesto crimen de agresión (López-Jacoiste Díaz, 2006).

De cualquier manera, al limitar el uso de la fuerza a lo dispuesto por el Capítulo VII de la Carta de NU, el mencionado texto se mantendría dentro de los parámetros vigentes del Derecho Internacional Público, al definir la responsabilidad de proteger más como un nuevo concepto que como una nueva norma. En este sentido, la Asamblea de Naciones Unidas prefirió no innovar normativamente, al evitar incorporar la propuesta completa de la Comisión Internacional sobre Intervención y Soberanía de los Estados (CIISE), que daría pie para la aceptación de la intervención unilateral por parte de los Estados en caso de inacción del Consejo de Seguridad, de la Asamblea General y de las Organizaciones Regionales, lo que implicaría, incluso, una modificación del concepto moderno de soberanía, así como la consolidación de la responsabilidad de proteger como norma del DIP (Añaños Meza, 2010, p. 235).

No obstante, la sola habilitación de la intervención -incluso no armada- en el ámbito internacional entraría en contradicción con el principio fundante del DIP de no intervención en los asuntos internos de otro Estado (Barboza, 2008; Bosé y Fernández Puyana, 2017). Ello sobre todo, teniendo en cuenta que los habilitados serían, en principio, los países más poderosos y los intervenidos, los marginales (Añaños Meza, 2010). Pues en términos fácticos resulta casi impensable la viabilidad de una intervención justificada en un país central. Incluso cuando pueda serlo teóricamente, el texto del citado párrafo 139, que se refiere a la intervención forzosa, lo hace en el marco del Capítulo VII de la Carta de Naciones Unidas, donde establece el marco de actuación del Consejo de Seguridad, en el cual los cinco miembros permanentes -China, Francia, Federación de Rusia, el Reino Unido de Gran Bretaña e Irlanda del Norte y los Estados Unidos de América- tienen poder unilateral de veto (Barboza, 2008). El principio constituiría, entonces, un refuerzo del poder hegemónico que se arrogan estos países a través de su rol en el Consejo de Seguridad.

Desde esta lógica de la hegemonía, no solo estos casos excepcionales de uso de la fuerza sino cualquier aplicación de este principio supondría una contribución a la consolidación de los poderes transnacionales, pues tales casos de excepción significan una aplicación de la responsabilidad de proteger como reacción. Sin embargo, este principio supone, además, otras áreas de responsabilidad como son 
la de prevenir, reconstruir y reaccionar sin uso de la fuerza (Añaños Meza, 2010). Interpretadas a través de la lógica liberal del poder, estas áreas de responsabilidad podrían servir también para habilitar la intromisión de los países centrales en las políticas internas de los países periféricos. La responsabilidad de prevenir, por ejemplo, podría ser utilizada para marcar lineamientos en cuestiones de política económica, de salud o alimentaria. Con esta modalidad top-down de aplicación, el principio de responsabilidad de proteger no se diferenciaría de facto de la intervención humanitaria.

Esta modalidad top-down es la expresión concreta de un enfoque liberal respecto del principio de responsabilidad de proteger, el cual, asociado a un paradigma jurídico hegemónico, se centra en la autoafirmación de las libertades y la reivindicación de derechos individuales. En este esquema, la discusión en torno al principio queda reducida a la habilitación técnico-jurídica de la intervención (López-Jacoiste Díaz, 2006; Añaños Meza, 2010). La responsabilidad de proteger viene, entonces, a reforzar el desequilibrio de poderes imperante en la comunidad internacional, el cual sistemáticamente queda disimulado por principios jurídicos formales como son la igualdad soberana de los Estados o la democracia liberal, en tanto participación general en las decisiones comunes (Añaños Meza, 2010).

Sin embargo, y allí reside el potencial del concepto, la responsabilidad de proteger surge como alternativa discursiva a la intervención humanitaria, para poner el acento en las urgentes necesidades de los posibles beneficiarios de la acción, antes que en las prerrogativas de aquellos que vendrían a intervenir (López-Jacoiste Díaz, 2006).

Este cambio discursivo no acarrea consigo, evidentemente, una transformación automática del paradigma jurídico ni la superación de los manifiestos desequilibrios de la comunidad transnacional que históricamente dieron lugar a sistemáticas intervenciones (Chimni, 2006). Pero sí puede posibilitar la incorporación de un parámetro ajeno a la lógica autorreferencial y hegemónica vigente en el derecho moderno occidental. Precisamente es ese potencial que encierra la responsabilidad de proteger el que pretende ponerse de manifiesto en este trabajo, en cuanto contendría en sí el germen a partir del cual se puede hacer efectivo el traspaso de un derecho centralizado en la autoafirmación identitaria, a una forma descentralizada de este mismo, a un derecho enfocado en la no-indiferencia por la alteridad.

\section{Del orden identitario a la constelación plural}

El cambio de paradigma que significa la comprensión del orden jurídico a partir de la noción ética de responsabilidad excede ampliamente el área del derecho 
internacional, pues invierte la lógica identitaria y garantista del sistema jurídico moderno en sí. Dicho sistema, constituido como estructura racional de garantía de la identidad hegemónica de un sujeto ideal de derechos, viene a regular la convivencia de individuos autónomos, que se organizan libremente bajo el imperio de un sujeto también ideal: el Estado soberano (Hughes, 1998).

Este impone una armonía basada en la unidad uniforme de la razón. La socialidad, la convivencia intersubjetiva, se constituye en este paradigma a partir del saber. La comunidad de los individuos no es otra que la unidad de la síntesis aperceptiva del "yo pienso" a través de la cual se logra el armisticio de la no-agresión mutua. El mutuo entendimiento se da aquí en un diálogo llamado a detener la violencia a través de la conducción de los sujetos interlocutores a "entrar en razón”, a ser razonables (Levinas, 1994). Se instituye así una forma de paz racional concebida como unanimidad, que cancela las diferencias en una coincidencia formal superadora de los obstáculos que impiden su realización.

Esta forma de paz hegemónica, soberana, encuentra serias dificultades para conducir a un diálogo efectivo y auténtico en escenarios plurales y complejos. Se genera, de esta forma, un enfrentamiento entre seres distintos, autorreferentes, decididos a luchar en la competencia por la existencia. Esta forma de raíz hobbesiana de concebir lo social suscita una naturalización del orden violento como algo innato o inherente a la esencia de los sujetos que solo ven en el otro a un contrincante que amenaza su libertad (Hobbes, 2003). El otro individuo constituye un adversario con el que hay que pactar para lograr una convivencia estratégica en la que nadie molesta a nadie y nadie se interesa efectivamente por nadie (Davy/Lenzen, 2013).

En cambio, la responsabilidad de proteger introduce en la noción de soberanía un aspecto debitorio ajeno al paradigma absolutista, autorreferencial y dominial del Estado moderno (Piedrahita Ramírez, 2015; Mattei, 2013), al reactivar el carácter pasivo de la personalidad jurídica soslayado por la clásica comprensión dominial, en donde prima un rol del Estado ante todo como sujeto activo de derechos (López-Jacoiste Díaz, 2006). En este carácter pasivo, debitorio, reside justamente el potencial ético de la responsabilidad de proteger, pues hace referencia a una relación con la alteridad, anterior a todo ordenamiento, que pone en cuestión cualquier ánimo hegemónico, cualquier ánimo totalizador. Este cuestionamiento que desestabiliza toda hegemonía constituye un punto de partida fundamental para asegurar una paz efectiva en el contexto de diversidad mundial.

En este sentido, la sustitución del concepto de intervención humanitaria por el de responsabilidad implica una reformulación del concepto mismo de soberanía. La comprensión de esta como autoridad cede paulatinamente frente a un nuevo 
abordaje como protección. La soberanía dejaría de estar identificada exclusivamente con el control y el dominio sobre un territorio y su población, para pasar a ser comprendida como responsabilidad por ellos (Piedrahita Ramírez, 2015; López-Jacoiste Díaz, 2006; Añaños Meza, 2010).

Se trata de rastrear, como trasfondo de esta paz formal -necesaria y evidente- otra forma de paz que la precede por su originariedad y primordialidad (Messina, 2012). Paz difícil, compleja, dramática, que se realiza ante todo como no-indiferencia, como tensión dinámica, como relación de proximidad, como encuentro con el otro como otro más allá de todo aglutinamiento en torno a una "verdad común" (Levinas, 1994, p. 12).

Si logra subvertir la lógica del poder que impera en las relaciones internacionales, la responsabilidad de proteger puede contribuir a reformular las condiciones de supervivencia del DIP. La apelación a la alteridad, a lo diferente, a lo ajeno, puede contribuir a entablar un nuevo esquema plural de convivencia en una comunidad tan diversa como la constelación transnacional.

\section{De la pretensión al deber: El carácter debitorio de la responsabilidad de proteger}

El carácter 'debitorio' de la responsabilidad de proteger habilita la revisión de la estructura garantista occidental del orden jurídico, que privilegia los derechos y las prerrogativas (Habermas, 1999) como mecanismos de aseguramiento de la autoposición del sujeto de derechos, a través de la recuperación del sentido y el valor del aspecto pasivo de la personalidad jurídica, que se sigue de la responsabilidad por los otros.

Para la teoría moderna, el ordenamiento jurídico tiene por objeto asegurar el cumplimiento de las pretensiones del sujeto de derechos. Por ello no es casualidad que orden jurídico sea sinónimo de derecho. Esta teoría hace un gran esfuerzo para justificar tal identificación, otorgándole al término derecho una doble función semántica como orden jurídico -derecho objetivo- y como pretensión individual -derecho subjetivo-. Esta escisión dual no es inocua, sino que implica una asimilación del orden a tales pretensiones. La lógica de la identidad, que subyace al orden moderno, es una lógica del poder, poder para sí. Es una lógica autorreferencial que busca asegurar la posición del sujeto a toda costa (Bonet de Viola, 2018).

Esta lógica se plasma en el paradigma de la paz liberal, basado sobre un concepto de seguridad que refiere al aseguramiento de la autoposición del sujeto soberano. Se trata de la lógica que fundamenta el otorgamiento del Premio Nobel de 
la Paz a Barack Obama, quien al recibirlo, advirtió que su rol fue siempre el de defender los intereses de su nación (Obama, 2009). La paz que promovió fue la de la tranquilidad y aseguramiento del Estado norteamericano, que coincide en la actualidad con el centro del poder hegemónico mundial. Desde esta lógica, la responsabilidad de proteger viene tan solo a reforzar el humanismo egocéntrico que sostiene al paradigma de la identidad.

En cambio, el concepto de responsabilidad prioriza la relación con la alteridad por sobre la autoposición de la identidad (Ciaramelli, 2003), jerarquizando el aspecto pasivo de la personalidad por sobre el aspecto activo. Esta prioridad no significa una subordinación valorativa del derecho frente al deber, sino el señalamiento de una relación anterior al derecho, constitutiva de la posición que el derecho asegura. Hace referencia a una relación ética, que acontece como respeto hacia el aspecto irreductible de toda alteridad. Se trata de una relación primera, anterior a todo ordenamiento y que precisamente por eso no se deja cristalizar en una norma, en cuanto que dicho vínculo acontece en la modalidad de un exceso, de una exuberancia ética, que no puede ser sino de naturaleza extrajurídica (Teubner, 2010).

Este carácter extrajurídico de la responsabilidad puede ampliar el sentido de la configuración vigente, contractual, de la responsabilidad de proteger al retomar la dinámica primigenia de la socialidad como preocupación por la alteridad, como respeto por la 'irreductibilidad infinita del otro' (Derrida, 2001). Esta forma primera, originaria, de la responsabilidad es pre-contractual, pues no tiene su origen en la libertad de los individuos involucrados. Es una forma de responsabilidad 'anárquica' (Levinas, 2001), sin principio ni origen. Se trata de una comprensión de la responsabilidad como 'desinterés'. Más precisamente de una forma paradójica del interés: se trata de un 'interés desinteresado', esto es, de un interés paradójico, sin retorno, sin rédito (Levinas, 2004, p. 198).

El carácter anárquico de este aspecto debitorio de la responsabilidad significa que esta no puede exigirse, no puede planearse, pues tiene una dinámica acontecimiental y asimétrica, la dinámica del don y la gratuidad. Esta dinámica es ajena a todo orden, escapa a todo plan. En cambio, incorpora una aspecto de proximidad, de acercamiento, de amistad (Derrida, 1998) entre las diferencias, totalmente impensable para la lógica hostil de la autorreferencialidad y la hegemonía.

En este sentido, la responsabilidad de proteger pone en cuestión la lógica económica sobre la que se asienta el derecho vigente, lógica de la reciprocidad, del do ut des, lógica que hace lugar a un orden fundamentado exclusivamente en el reconocimiento recíproco de derechos y obligaciones. Esta reciprocidad, este 
espacio simétrico regulado por el orden jurídico es interpelado, en efecto, a partir del orden asimétrico, extrajurídico, de la responsabilidad.

El establecimiento de la prioridad de lo relacional ético por sobre el orden de lo meramente jurídico-normativo, contribuye a repensar la "pluralidad" formal establecida a partir del orden del derecho, en tanto derivada de una pluralidad más originaria, esto es, la multiplicidad de una sociedad de únicos donde todos son responsables por todos (Levinas, 2001). Ello puede contribuir a recuperar las diferencias suprimidas por el esquema moderno absolutista de socialidad que tan solo logra reunir a las diferencias en una unidad de conciencias múltiples que han entrado en el mismo pensamiento, pero donde queda suprimida su recíproca alteridad (Levinas, 1994).

Al respecto, el concepto de responsabilidad puede contribuir en última instancia a revisar la funcionalidad del derecho como regulador de una sociedad homogénea. En cambio la recuperación de estas dimensiones extrajurídicas, históricas, irreductibles al derecho y a la ontología, resignifica la función del derecho como práctica, como orden dinámico de un esquema plural de socialidad (Ciaramelli, 2009). En este esquema, la responsabilidad viene a ejercer una función de mediación entre lo relacional -lo extrajurídico- y el orden normativo del derecho cristalizado.

Por eso, el carácter debitorio de la responsabilidad subvierte la lógica del poder, porque el deber que surge de la responsabilidad de proteger es anterior a toda cristalización, a toda institución. Esta anterioridad de la responsabilidad ética puede incorporar al derecho un aspecto de hospitalidad como apertura total a las diferencias, como acogida de la alteridad. Puede subvertir la dinámica regulatoria verticalista del derecho, para repensarlo como un orden "horizontal", como servicio, como entrega, más allá de toda reciprocidad.

La responsabilidad efectiviza así una paz que no constituye el resultado de un acuerdo ex post, sino la condición misma de lo político como hospitalidad (Derrida, 2001), como espacio simbólico (Ciaramelli, 2003), como espacio a partir del cual crece y se respeta la diferencia. Esta paz no significa la mera armonía de sí consigo mismo, ni coincide con la quietud de la conciencia que descansa en su "zona de confort", sino que por el contrario, paradójicamente, se realiza como inquietud, como desasosiego generado por la responsabilidad que perturba la conciencia y la orienta hacia el otro. Es la paz de la pre-ocupación permanente e infinita por la alteridad (Levinas, 2006; Messina, 2012). 


\section{De la hostilidad a la hospitalidad}

El carácter debitorio de la responsabilidad de proteger encierra un potencial subversivo no solo respecto de la comprensión clásica y estatista del derecho internacional y de los derechos humanos, sino del derecho moderno. Al poner el acento en la diferencia, en la alteridad, la responsabilidad de proteger puede mover el eje del derecho hacia los márgenes de la identidad. Puede así hacer lugar a esa irreductibilidad, a esa trascendencia infinita del otro (Teubner, 2010), aplazada por el dominio soberano de las identidades modernas.

Ello significa habilitar una forma de derecho diferente, ya no como orden de aseguramiento de pretensiones, sino como orden de la responsabilidad, como orden de acogida de las diferencias, como orden de la hospitalidad. Significa revisar la lógica hobbesiana de la paz formal, paz de la mera coexistencia no beligerante entre sujetos indiferentes, que en última instancia favorece, de facto, al más fuerte. Implica cuestionar la lógica moderna de la individualidad y de la autorreferencialidad. Este cuestionamiento afecta, por otra parte a la "buena conciencia" respecto del status quo, conciencia a partir de la cual se llevan a cabo guerras aparentemente legítimas de suyo (Levinas, 2006).

Ello significa, en otras palabras, habilitar el paso de un derecho regulador de la hostilidad a un derecho 'gestor' de la hospitalidad (Derrida, 2000; Penchaszadeh, 2011). Implica dar lugar a la 'extravagante hipótesis' que conlleva la revisión de los términos del contrato social. El cual pasaría de regular la "inevitable" hostilidad recíproca a limitar una generosidad "extra-ordinaria" que de suyo no conoce límites. En otras palabras, se regula así no el exceso de un odio pretendidamente natural, sino la 'exuberante responsabilidad de todos por todos' (Levinas, 1991; Abensour, 2005). Esta alternativa que surge de la responsabilidad propone la posibilidad de imaginar, entonces, la convivencia como el ordenamiento de la exuberancia de los deberes recíprocos que surgen de la responsabilidad. Es decir, como la limitación de los "excesivos" deberes de todos por todos.

\section{Perspectivas}

El enfoque de la hospitalidad imprime un nuevo carácter al debate sobre la extraterritorialidad que se inaugura a partir del principio de la responsabilidad de proteger. Al desplazar el eje del derecho de la esfera de la identidad; la pretensión y el dominio, a la esfera de la alteridad, la responsabilidad y la hospitalidad, toda acción extraterritorial, toda intervención queda subordinada a la lógica diferencial de la alteridad. 
Esta lógica significa pensar cualquier intervención desde la perspectiva de la alteridad, como cuestionamiento de la propia identidad interviniente. Ello reconfigura los límites de los ámbitos de aplicación del principio de responsabilidad de proteger, tanto materiales, personales como territoriales. Pues tales límites adquieren su sentido tan solo como aseguramiento de la identidad.

Una revisión de los límites materiales de este principio a partir de esta reconfiguración comportaría la habilitación de su efectiva aplicación no solo para los cuatro casos de violaciones de derechos nombrados en la citada Resolución de la AGNU, sino frente a toda violación de los derechos humanos del otro.

Por su parte, pensar los derechos humanos como 'derechos del otro' (Levinas, 2002, p. 131), implica una revisión de los límites personales del principio que se traduciría en una responsabilidad de todos por todos. Ello remueve, a su vez, las fronteras estatales, territoriales de aplicación. Pues cuestiona la limitación que reduce el ámbito de aplicación a los Estados dentro de su territorio y solo eventualmente de un territorio ajeno. Ello implicaría, de alguna manera, un reconocimiento del estatus de toda la comunidad global como sujeto activo y pasivo de los derechos de la alteridad.

Aunque la aplicación de este cambio de paradigma no sea inmediata, ni pueda serlo tal vez en modo alguno, pueden rastrearse ya algunas posibles concreciones.

Por ejemplo, a esta lógica aludía el Consejo de Ética alemán cuando hacía referencia a la responsabilidad de proteger como fundamento de un deber de cada país y de la comunidad internacional de garantizar la seguridad alimentaria a nivel mundial (Deutscher Ethikrat, 2011). Lo mismo podría pensarse respecto de la salud, la vivienda o, en definitiva, de todo aquello que contribuye a la realización de un nivel de vida digno. La responsabilidad de proteger comprometería, en este sentido, a toda la comunidad global a procurar, de alguna forma, un nivel de vida digno para todas las personas, lo cual, a su vez, llevaría a cuestionar toda medida económica, política o jurídica que atente contra su realización efectiva.

Con dicho esquema, este principio podría conducir, por ejemplo, también a repensar las formas vigentes de intervención humanitaria (lo mismo vale para la asistencia social), las cuales, en un sistema top-down, contribuyen a menudo a potenciar no solo las jerarquías sociales, sino también las crisis económicas locales de los países periféricos. ${ }^{6}$

6 A través de la ayuda humanitaria se pueden destruir los mercados internos al ofrecer alimentos gratuitos o a muy bajo costo. Ello suele causar un daño mayor a los países intervenidos, que luego de la retirada de los organismos asistenciales quedan, inclusive, desprovistos de sus propios medios de subsistencia. 
Implicaría también revisar el sistema liberal de comercio mundial, a través del cual los países centrales legitiman el sistema de acaparamiento de tierras en los países periféricos, que llevan adelante empresas transnacionales en perjuicio de las poblaciones locales (Bernstorff, 2012).

Significaría poner en cuestión los mecanismos vigentes de producción global de mercancías, que continúan sosteniendo sistemas extractivistas en perjuicio no solo del acceso de las poblaciones de los países periféricos a sus propios recursos, sino también en desmedro del medio ambiente a nivel global y de las generaciones futuras.

Implicaría, a su vez, revisar el sistema internacional de promoción de las inversiones en investigación y desarrollo, que conduce a la monopolización del conocimiento y las tecnologías y a la mercantilización de las actividades inventivas. Ello, en favor de la promoción del acceso global a las tecnologías, sobre todo de aquellas que tengan que ver con la realización de derechos fundamentales como la salud, la alimentación o la educación.

En definitiva, esta responsabilidad de proteger, al replantear los términos hegemónicos no solo de las organizaciones internacionales sino incluso del orden mundial, podría contribuir a la gestación de una regulación transnacional que respete la dinámica plural y diversa de la comunidad global.

\section{Bibliografía}

Abensour, M. (2005). La extravagante hipótesis. Revista de Filosofía, 61, 169-196.

AGNU, Asamblea General de Naciones Unidas. (2005). Documento Final de la Cumbre Mundial de 2005. Resolución A/RES/60/1.

Annan, K. (2005). Un concepto más amplio de la libertad: Desarrollo, seguridad y derechos humanos para todos. Informe del Secretario General Kofi Annan para la Cumbre Mundial 2005. AGNU: A/59/2005.

Añaños Meza, C. (2010). La "responsabilidad de proteger" en Naciones Unidas y la doctrina de la "responsabilidad de proteger." Anuario Mexicano de Derecho Internacional, 10, 199-244.

Barboza, J. (2008). Derecho internacional público (2. da Ed.). Zavalia.

Bernstorff, J. (2012). Land Grabbing und Menschenrechte: die FAO Voluntary Guidelines on the Responsible Governance of Tenure. Die FAO Voluntary Guidelines on the Responsible Governance of Tenure. Duisburg: INEF. Retrieved from http://www.humanrights-business. org/files/landgrabbing_final_1.pdf 
Bonet de Viola, A. M. (2018). Derechos sociales, normas de acceso y democracia. La agenda de los derechos humanos para una convivencia solidaria. Revista Latinoamericana de Derecho Social, 26, 3-27.

Bosé, M., \& Fernández Puyana, D. (2017). La historia de la paz en Occidente. UNESCO, University for Peace.

Cendejas Guízar, J., \& Merino Pérez, L. (2016). Acción colectiva en la construcción social de la paz y la seguridad. La paz y la seguridad como bienes comunes. Cultura y Representaciones Sociales, 10(20), 9-41.

Chandler, D. (2004). The Responsibility to Protect? Imposing the 'Liberal Peace.' International Pacekeeping, 11(1), 59-81. https://doi.org/10.1080/1353331042000228454

Ciaramelli, F. (2003). Lo spazio simbolico della democrazia. Città Aperta ed.

Ciaramelli, F. (2009). Instituciones y normas: Sociedad global y filosofía del derecho. Trotta.

Chimni, B. S. (2006). Third World Approaches to International Law: A Manifesto. International Community Law Review, 8(1), 3-27. https://doi.org/10.1163/187197306779173220

Davy, U., \& Lenzen, M. (2013). Einleitung: Demokratie morgen. In U. Davy \& M.

Derrida, J. (1998). Políticas de la amistad. Trotta.

Derrida, J. (2000). Dar la muerte. Paidos.

Derrida, J. (2001). ¡Palabra! Instantáneas filosóficas. Trotta.

Deutscher Ethikrat (2011): Die Ernährung der Weltbevölkerung - eine ethische Herausforderung. Tagungsdokumentation - Vorträge der Jahrestagung des Deutschen Ethikrates. Berlin.

Diez de Velasco, M. (2013). Instituciones del derecho internacional público. TecnosMa.

GAN, Grupo de Alto Nivel del Secretario General sobre las amenazas los desafíos y el cambio. (2004). Un mundo más seguro: La responsabilidad que compartimos. Naciones Unidas.

Habermas, J. (1999). Der interkulturelle Diskurs über Menschenrechte. In M. Brunkhorst, Hauke, Köhler, Wolfgang; Lutz-Bachmann (Ed.), Recht auf Menschenrechte : Menschenrechte, Demokratie und internationale Politik (pp. 216-227). Suhrkamp.

Hobbes, T. (2003). Leviatán. Losada.

Howard, M. (2000). La invención de la paz. Reflexiones sobre la guerra y el orden internacional. Salvat.

Hughes, C. L. (1998). The primacy of ethics: Hobbes and Levinas. Continental Philosophy Review, 31(1), 79-94-79-94. http://www.springerlink.com/index/TJOR48871554435W.pdf 
ICISS, International Commission on Intervention and State Soveraignity. (2001). La responsabilidad de proteger. Autor.

Leal Moya, L. (2005). Seguridad humana. La responsabilidad de proteger. Boletín Mexicano de Derecho Comparado, XXXVIII, 1117-1138.

Lenzen (Eds.), Demokratie morgen. Überlegungen aus Wissenschaft und Politik (pp. 7-15). Transcript.

Levinas, E. (1991). Ética e infinito. Visor.

Levinas, E. (1994). El diálogo. Revista de Filosofia, 4(5), 7-22.

Levinas, E. (2001). Entre nosotros: Ensayos para pensar en otro. Pre-Textos.

Levinas, E. (2002). Fuera del sujeto. Caparrós Editores.

Levinas, E. (2004). Le primat de la raison pure pratique. Das Primat der reinen praktischen Vernunft. In N. Fischer (Ed.), Kants Metaphysik und Religionsphilosophie. Meiner Verlag.

Levinas, E. (2006). Paz y proximidad. Revista Laguna, 18, 143-151.

López-Jacoiste Díaz, E. (2006). La responsabilidad de proteger: Reflexiones sobre su fundamento y articulación. Anuario Español de Derecho Internacional, 22, 285-315.

Luengo Zarzoso, M. (2016). La responsabilidad de proteger como paradigma de la seguridad humana. Posición española y tipología militar. Boletín IEEE, 1(Enero - marzo), 990-1089.

Mattei, U. (2013). Bienes comunes. Un manifiesto. Trotta.

Messina, A. L. (2012). La paz como primer lenguaje. Paz y política. En E. Levinas. Ideas y Valores, 61(150), 145-167.

Obama, B. (2009, December 10). Nobel Peace Prize acceptance speech. Retrieved from http:// www.msnbc.msn.com/id/34360743.

Penchaszadeh, A. P. (2011). Política, don y hospitalidad en el pensamiento de Jacques Derrida. Isegoría, 44, 257-271. file://C:/Users/Anita/Downloads/729-731-1-PB.pdf

Piedrahita Ramírez, L. F. (2015). La soberanía como responsabilidad y los fundamentos del nuevo intervencionismo humanitario. Estudios de Filosofía, 51(51), 45-74. https://doi. org/10.17533/udea.ef.n51.a04

Teubner, G. (2010). Justicia autosubversiva: ¿Fórmula de contingencia o de trascendencia del derecho? Anales de La Cátedra Francisco Suárez, 44, 217-248. 